\title{
Anti-Crisis Legal Regulation in the COVID-19 Conditions: The System of Restrictions or Creative Legal Impact
}

\author{
Submitted 06/06/20, 1st revision 14/07/20, 2nd revision 19/08/20, accepted 15/09/20 \\ Tatyana V. Shatkovskaya ${ }^{1}$, Gennady S. Pratsko ${ }^{2}$, Irina S. Maslova ${ }^{3}$, \\ Zura D. Dinaeva ${ }^{4}$, Mikhail M. Kanaev ${ }^{5}$
}

\begin{abstract}
:
Purpose: The purpose of this study is to scientifically and critically comprehend the experience of European countries in overcoming the COVID-19 consequences and, on its basis, to construct an optimal model of modern anti-crisis legal regulation.

Design/Methodology/Approach: The authors constructed the anti-crisis legal regulation model and studied using the systematic scientific approach and the method of analysis and programming to reconstruct typical patterns of social relations, basing on knowledge about the regulation object and using legal tools and techniques. Through the methods of modeling and reconstruction the authors could develop and substantiate the anti-crisis model structure. In order to determine the national characteristics of the subject, the authors used the comparative legal method as well as statistical, system-structural and functional methods.

Findings: As a result of the study, the authors made the conclusions about the essence of the crisis impact caused by the COVID-19 on the mechanism of legal regulation, about the features and principles of anti-crisis legal regulation, in particular, its subject, method, goals and tasks, and means of legal influence. The authors determined the conditionality of the anti-crisis legal regulation model by the initial legal principle underlying it, and the national legal awareness features. The authors prove that total restrictions make the population to overstep law, thereby reduce the authority of the law and trust in the legal bodies, deform legal awareness, violate existing legal relations and relationships.

Practical Implications: The results of the study, based on a wide range of empirical data, are necessary for the development of state programs for the business normalization and the economy recovery, as well as for the formation of national strategies for anti-crisis legal regulation and guidelines, recommendations and clear procedures for the public emergency introduction. In particular, the authors proposed to use political and legal programming as a method of legal regulation in a crisis.
\end{abstract}

Originality/Value: The novelty of the article is to develop the structure, models and features of anti-crisis legal regulation in COVID-19 pandemic conditions on the analysis and generalization of the experience of some European countries. The study proves the low

\footnotetext{
${ }^{1}$ The Russian Presidential Academy of National Economy and Public Administration, Moscow, Russian Federation, shatkovskaya.tv@gmail.com;

${ }^{2}$ Rostov State Transport University, Rostov-on-Don, Russian Federation, gpip@ rgups.ru;

${ }^{3}$ Rostov State University of Economics, Rostov-on-Don, Russian Federation, irinasmaslova@yandex.ru;

${ }^{4}$ Chechen State University, Grozny, Russian Federation, dinaeva-zura@mail.ru;

${ }^{5}$ The Russian Presidential Academy of National Economy and Public Administration, Department of Theory and History of Law and State, Moscow, Russian Federation, mishakenny07@yandex.ru;
} 
effectiveness of the restrictive anti-crisis model of legal regulation in comparison with the creative legal impact both in conditions of a crisis and in overcoming its negative consequences.

Keywords: Legal regulation, methods of legal influence, anti-crisis model of legal regulation, COVID 19, state of emergency, legal prohibition, legal incentive, permissions.

JEL codes: $G 18, K 10$.

Paper type: Research article.

\section{Introduction}

The modern social crisis caused by global informatization and large-scale cognitive changes connected with it is aggravated by the COVID-19 pandemic. The experience in Russia and abroad of overcoming social crises proves that the lack of natural social harmony can be overcome in turn by the ordering of social relations with law, supported by new beginnings, expanded content in accordance with new challenges.

The crisis is not a complete rejection of the social ideals and their legal foundations. The sphere of legal regulation should be revised in order to eliminate legal structures forcibly restraining the implementation of requests, aspirations and legitimate goals of modern states. At the same time, it is necessary to overcome the disastrous illusion that it is possible to achieve social improvements by simple external legal forms, and moreover by the use of ready-made solutions from the past legal experience.

The COVID 19 pandemic has actualized terrible problems. Humanity was seemed to solve forever for example the massive spread of infectious diseases. People all over the world, connected by the globalization, for the first time has faced with such a largescale spread of infection and the need to overcome its consequences simultaneously with the use legal means and within legal limits.

The modern situation clearly shows that it is necessary to develop options for anticrisis legal regulation. The lack of well-developed models of legal solutions for emergencies leads that states make the simplest decisions and use the most obvious methods, such as the introduction of prohibitions and other restrictions. At the same time, legal restrictions are effective only for a short time, and in the long term they have a detrimental consequences on public relations, destroying the social ties, reducing the authority of law and state power.

Therefore, in our opinion a comprehensive study of the anti-crisis legal regulation model is an important task of modern law. The purpose of this article is to make a scientific and critical understanding of the experience of European states in overcoming the consequences of COVID- 19 and on its basis to construct an optimal model of modern anti-crisis legal regulation. 


\section{Methodological Approaches to the Anti-crisis Legal Regulation Model Formation}

Crisis phenomena in the legal sphere are connected with social cataclysms. According to P.I. Novgorodtsev (1909), who divided such crises into two types, the first type of crisis phenomena leads to the complete collapse of previous legal concepts caused by deep life problems. The second type crises are expressed in upcoming radical change for overcoming social antagonism. In both cases, the crisis means legal uncertainty, doubts, and the need for scientific and critical analysis of the ideas forming the basis of the legal regulation theory (Alekseev, 1919; Ilyin, 1994; Sorokin, 2005). It is only on the basis of this analysis it is possible to development clear and understandable state goals, as well as a specific instructions for their legal support.

Despite all the negative consequences, globalization and informatization of the modern legal space, contributed to the intensification of legal communication as well as the development and the use of new means of legal regulation for example legal incentives aimed at supporting creative actors creating and developing the modern information interaction methods. The legal standards introduction has improved the quality of legal regulation by consolidating, implementing and using the best global regulatory practices.

A legitimate compromise as a means of ensuring a reasonable balance between the norms of international law and national legislation in making legal decisions (Resolution of the Constitutional Court of the Russian Federation, 2016 No. 12 P).

The crisis caused by the COVID- 19 pandemic, if not stopped, then made significant adjustments to the historical process of developing legal regulation tools in the direction of a consistent expansion of individual legal freedom and forms of supranational social and solidarity interaction. Firstly, was reflected in the restoration of the borders of state legal regulation, the strengthening of the role of national law and the widespread decline in the authority and even refusal to comply with the norms of international law. For example, in Spain, the trend of decentralization has been replaced by a new round of centralization of legal regulation.

Secondly, the crisis has intensified moral and legal contradictions both within and between certain social groups. This leads to an inevitable conflict behaviors, mutual struggle, and as a consequence, an increase in the use of punitive and coercive as opposed to means of legal regulation, for example, conducting additional penalties for individuals and organizations for violation of sanitary-epidemiological requirements.

Thirdly, the COVID- 19 pandemic has provoked a global crisis on a global scale, creating the need for comprehensive solutions to problems in all areas of human life, primarily preventing threats to the lives and health of millions of people. On 30.01.2020 the World Health Organization declared COVID -19 epidemic a public health emergency of international significance, and to date it has reached 188 
countries. Sanitary and epidemiological restrictions for an indefinite period of time become a reality of modern life, generating a high degree of uncertainty in socioeconomic relations.

Fourthly, COVID-19 pandemic revealed gaps and insufficiency of emergency legislation in most European States, in particular, the scope and limits of emergency powers of public authorities, parliamentary and judicial control, the possibility of introducing severe restrictive measures by the government without parliamentary approval, the definition of the concept of General (non-individualized) losses and the procedure for their compensation, etc.

In the conditions of the crisis the legal regulation does not change its destination. It teaches people to self-limit their instinctive impulses and arbitrary encroachments, to consciously observe the legal form and legal limit in actions by preserving, accumulating, explaining and simplifying the disciplining rules of behavior and ways of implementing them, which regulate and expand the indisputable sphere of social relations.

Thus, the model does not change the essence of legal regulation, that is, the original legal regulation that remains constant in any life changes, and therefore the operation of law in the post-COVID-19 crisis does not allow us to speak about the appearance of another law. At the same time, anti-crisis legal regulation has a peculiar purpose and objectives, as well as a certain set of legal means of rapid legal response.

Anti-crisis legal regulation has an atypical subject of legal impact, complicated by the large-scale destruction of established public relations and forms of social solidarity, as well as its expansion due to the emergence of relations that are not regulated by the norms of positive law. And the more acute and deeper given antagonism, the harsher the system of punishments applied, used as a means of protecting the group from death and disintegration. Thus, during the period of the COVID- 19 pandemic restrictive measures are used in $90 \%$ of European States.

In General, the anti-crisis model of legal regulation is characterized by the following features:

- temporary in nature, as it is aimed at taking rapid response measures to the emergency consequences of the crisis and its subsequent overcoming, that is, it is designed for a restorative transition period of stabilization of the social system and ensuring security;

- national-territorial character, due to the need to preserve a state-organized order and life on a certain territory;

- atypical character, that is, it is carried out in a situation where it is impossible to apply a number of established norms of current positive law and generally accepted legal methods and means of influence; 
- determination from the nature of social contradictions and the degree of severity of socio-economic and political consequences that occurred as a result of the current crisis;

- -concentration of regulatory powers in the subjects of state-organized legal influence and limiting the independence of private subjects of individual and social legal regulation, curtailing the mechanisms of self-regulation and self-reproduction;

- imperative character, which is expressed in the dominance of a system of legal prohibitions that not only restrict property turnover, but also restrict private initiative, freedom of legal interaction and the implementation of personal legal interests;

- restrictive nature, means the absence of a balance between permissive and prohibitive measures in the legal system, the predominance of strict measures of legal influence with the possibility of using physical coercion to maximize the disciplining value of positive law, etc.

\section{The Content of the Anti-crisis Legal Regulation in the Context of the COVID 19 Pandemic}

The typological features of anti-crisis legal regulation identified above do not mean that this model has a universal character. In the context of the information society and the accomplished scientific and technological revolution, anti-crisis legal regulation has a number of features and requires the use of means different from previously approved methods of overcoming the crisis.

Creativity and ingenuity in combination with scientific rationality displace the value priorities of the last century. Therefore, in this historical situation, first of all, it is necessary to clearly define the goals and tasks of anti-crisis legal regulation and their consistent implementation in the legal space. At the same time, goal setting in the context of overcoming the crisis should not conflict with General legal principles, the foundations of the constitutional system of the state and generally comply with the strategy its legal development (Shatkovskaya et al., 2020).

The subject of anti-crisis legal regulation requires a clear study. It should include only those social relations that need atypical legal mediation by state-power subjects and can be modeled in the format of subjective rights and legal obligations. Anti-crisis legal regulation implies a reasonable narrowing of the sphere of private autonomy. At the same time, social space is being expanded, that is, the area of external and compulsory intervention for obtaining a legal result, that corresponds to the goal ensuring the role of law and order. Therefore, it is extremely important to realize that the legal order consists of the matter of legal communication of individuals as independent members of one whole, who have rights and duties, and not as objects or means of legal influence.

Thus, the current anti-crisis model of legal regulation is generally defined by two principles: freedom of a disciplined individual with legal qualities or the forced 
organization of law and order by state authorities. The choice of one of these principles or their correlation determines the content and form of the model and the corresponding legal regulation in the state. Based on this, techniques and means of influence are selected, synthesized or developed.

The method of anti-crisis legal regulation is characterized by a complex structure, including a set of legal ways and means. Some of them only need to adapt to new conditions. At the same time, the emergence of a number of relations, connections and behavioral acts atypical for normal life requires the creation or synthesis of new methods of legal influence. Thus, taking into account the fact that modern social systems are characterized by sociologists as programmable (Touraine, 1969) it is advisable to develop certain samples. The latter represents an ordered set of regulatory features of the system being created, which determines the mode of achieving goals and programming tools.

The programming method is an intellectual "transition bridge" between the analytical stage of legal research and the practical stage, characterized by the development of a system of concrete measures and actions for legal support of the planned priorities of state and legal development. Thus, the programming method serves as a link and tool for interaction of the main types of legal activities (theoretical and practical).

The subject of legal programming can be both public legal entities and various organizations that are interested in developing an integrated system of legal actions and tools for achieving priority goals in implementing long-term projects, overcoming problematic situations, introducing innovative research programs, preparing and implementing regulatory support for state forecasting and strategic planning of socioeconomic development of the Russian Federation.

Through political programming, a mechanism is formed to ensure the viability of this social system in accordance with the conditions and tasks set in the strategy and the existing growth points, as well as to prevent or overcome the imbalance of the system caused by innovations or changes.

In the field of legal regulation, this function is implemented using such tools as legal actions and means created on the basis of scientific analysis and examination of legal reality, taking into account its state in a certain time frame and the presence of internal and external sources for achieving the goals set in the strategies. At the same time, if the method of analysis in law is aimed at a comprehensive study of the object of study and the identification of patterns in the structure and development of the legal system, then the programming method is intended for formal institutionalization and organization of legal regulation of public relations, ordering social relations based on the goals and objectives, based on the acquired knowledge about the subject of regulation and through legal tools and technologies. 
The crisis caused by the COVID- 19 prompted the legal mediation of digital forms of legal activity and, accordingly, digital means of legal regulation. These include electronic signatures, centralized digital platforms (e-government and other government portals, registries, databases, commercial digital platforms), biometric identification of legal entities, electronic services, electronic document management and data exchange, and much more.

Summing up the above, we will draw some intermediate conclusions:

-anti-crisis legal regulation as a manifestation of the action of positive law from the outside has certain features that allow us to separate it from other models of legal regulation;

-anti-crisis legal regulation does not have the property of universality and is determined by the historical circumstances in which it is applied, the level of national legal consciousness, as well as the scale of the destructive consequences of the social crisis;

-the model of modern anti-crisis legal regulation, depending on the initial legal principle underlying it, can represent a system of restrictive legal measures of a coercive nature, carried out by authorized authorities and bodies in order to preserve the inviolability of the internal state order. Another variation of the model under consideration is aimed at maximizing the freedom and legitimate forms of communication of individuals disciplined by the law, who are aware of the need for self-restraint in the interests of the common good, and we call it creative. In addition, a mixed model is possible, combining the features of both models.

\section{Scientific and Critical Analysis of the Current Experience of Anti-crisis Legal Regulation in the Context of COVID 19: By Way of Discussion}

Modern experience of overcoming the consequences of the pandemic and ongoing epidemic COVID - 19 offers a unique opportunity to analyze the effectiveness of the above-mentioned different visibility models of legal regulation of the crisis, identify their positive and negative points. For maximum purity of the research experiment, the analysis will be carried out within the framework of the Romano-Germanic legal family (on the example of some European countries).

The isolation regime has become a distinctive measure of modern anti-crisis legal regulation aimed at preventing the spread of the COVID - 19. However, the legal support of this regime turned out to be different in European states. An example of restrictive models of legal regulation of crisis is the experience of Albania $(\mathrm{CoE}$, 2020c), Italy, Spain, Latvia and Moldovia, Russia, Romania and (CoE, 2020a), Serbia and (CoE, 2020b), Slovakia, Ukraine, France, Estonia and many other countries. This model is characterized by the introduction of the ban on freedom of movement, the closing meters of external and internal borders, canceling public events, special regime of the activities of government and other public organizations, institutions and enterprises, the transition to remote forms of work, learning and interpersonal skills 
and a number of other restrictions, in including human rights and freedoms, the introduction of special measures of state support for certain categories of the population, etc.

Radical preventive measures violating the constitutional rights of citizens were introduced by documents that had no normative significance, often without declaring a state of emergency or martial law, but with a consistent tightening of restrictive measures. Subsequently legal support for these measures was provided by government resolutions and additional laws, often adopted in violation of the procedure established in the legislation. For example, the government of Ukraine is introducing a nationwide quarantine and emergency measures since March 11, 2020 and only in April, the relevant legislative acts were adopted, including amendments to the law "on the protection of the population from infectious diseases".

The experience of introducing restrictive measures by government acts is more widespread. So, the government Italy 23.02.2020 introduced a state of emergency, the most severe measures were introduced in the region of Lombardy (CoM, 2020). In France it was announced a state of emergency in the area of health (March 22, 2020) for two months (with the possibility of extension only by law, and cancellation by a decision of the government). As a result, changes were made to the public Health Code (Code de lasanté publique). The law provides for increased penalties for violating the quarantine. Fines have been increased from $€ 38$ to $€ 135$ (and $€ 375$ in case of late payment). In some French cities (Nice, Menton, Perpignan, Montpellier, Bezier) imposed a curfew.

The Russian experience is characterized by the widespread use of prohibitive measures that generally correspond to the state of emergency according to the Federal Constitutional Law of 30.05.2001 No. 3 - FKZ " On State of Emergency", but without declaring such (a "high alert" regime was introduced). Certain measures violated or general legal principles. So, the rule about the inapplicability of the new rules to those acts and legal relations that arose earlier is not respected. For example, the Decree of the Government of the Russian Federation dated 06.07.2020 No. 991" On approval of the Regulation on the specifics of the execution of the contract for the carriage of passengers by air ...", which, among other things, gave the carrier the right to unilaterally change the terms of such an agreement or refuse to execute it. A reasonable exception to the rule is recognized only for the General good and mitigation of punishment for the offender, but as can be seen from the above, the introduced norms do not correspond to any of these cases.

The Russian experience is characterized by the widespread use of prohibitive measures that generally correspond to the state of emergency according to the Federal Constitutional Law of 30.05.2001 No. 3 - FKZ "On State of Emergency", but without declaring such (a "high alert" regime was introduced). Certain measures violated or general legal principles. So, the rule about the inapplicability of the new rules to those acts and legal relations that arose earlier is not respected. For example, the Decree of 
the Government of the Russian Federation dated 06.07.2020 No. 991 "On approval of the Regulation on the specifics of the execution of the contract for the carriage of passengers by air ...", which, among other things, gave the carrier the right to unilaterally change the terms of such an agreement or refuse to execute it.

The effectiveness of both types of models of anti-crisis legal regulation cannot be fully assessed at the moment. Thus, it is difficult to determine the losses that would not have been caused if the state had taken proper precautions, from those that would have been caused in any case (unavoidable losses caused by force majeure). However, it can be calculated quantitatively primarily based on certain data on the level of the main economic indicators, crime, the decline in the standard of living of the population and the level of mortality, etc.

Thus, in Russia, according to the Ministry of labor, registered unemployment is from April 1 to May 20, 2020. increased from 720 thousand to 1.7,7million people., and in June reached 2.8 million people. For comparison, in Italy, the unemployment rate rose by $7.8 \%$. Real incomes of the population in Russia fell by $8 \%$ compared to the same period last year. In the first half of 2020 for the first time, a strike involving 79people was registered. The population decreased by 182.9 thousand people, while for the same period last year by 65.3thousand people. The number of deaths exceeded the number of births by 1.4 times (https://gks.ru/storage/mediabank/hYbb0cRH/oper-062020.pdf).According to Russian Statistical Agency on 20.07.2020 777486 people were infected with COVID 19 of them died 12427 people. The country's GDP declined by $4.2 \%$ in the first half of 2020 .

In the EU countries that used the restrictive model, the economic indicators of the lockdown period are not so significant. However, according to European experts, the consequences of these measures and the risks they carry are more devastating in the long run. Thus, according to the Italian State Statistics Service, about 60\% of Italian firms reported a sharp drop in income (from 50 to 74\%) (ITSTAT, 2020) .

Interesting conclusions about compliance with the imposed restrictions can be drawn based on the analysis of traffic data in major European cities. For example, among the countries that have chosen a restrictive model of legal regulation, the most disciplined were Italians, Spaniards and French. Their traffic has decreased by 80 percent or more. In major Russian cities, for example, in Moscow, traffic decreased by about 36\%, which is comparable to German cities (Hamburg, Berlin) that did not introduce strict measures (Kommersant, 2020).

In the Italian and Spanish cities most severely affected by the coronavirus epidemic, car traffic has dropped by more than $80 \%$ compared to normal levels. These conclusions were reached by the German magazine "SPIEGEL ", analyzed the data of the Dutch company the TomTom - supplier of automotive devices the GPS navigation. In Vienna, traffic fell by 57\%, traffic in German cities fell not so much: in Berlin - by $36 \%$, in Hamburg - by 42 , in Cologne - by $42 \%$. For comparison, in 
Munich, the central city of Bavaria, where the state of emergency was declared, the figures were $38 \%$ (Kommersant, 2020).

In the long term, the measures taken by the states can be assessed by the criterion of "harmfulness". However, even now it is obvious that the restrictive measures have influenced the nature of crime. On the one hand, European and American states reported a sharp reduction in the level of street crime (on average by $20 \%$ ), road traffic offenses from 28 to $50 \%$. However, domestic violence has increased significantly (in some countries up to $120 \%$ ). At the same time, crime has been transformed. Thus, there has been a doubling of the number and new varieties of cyber-crime have appeared, for example, online fraud about, blackmail, online drug trafficking (TADVISER, 2020).

Crimes related to the spread of viral diseases, have been updated in new forms. Considering that the legislation of most European States (Norway, Sweden, Finland, Denmark, Czech Republic, Serbia, Bulgaria, etc.) (Penal Code of the Kingdom of Norway, LOV 20050520 28; Criminal Code of the Kingdom of Sweden, Brott stalk (1962:700), Criminal Code of Czech Republic, Act 40/2009 Coll, Criminal Code of the Republic of Bulgaria) contain when criminal penalties are imposed for the transmission of infectious diseases, including their negligent distribution, as well as for the possibility of an asymptomatic course of COVID 19, hundreds of thousands of people become potential criminals. It is obvious that no system is able to organize criminal prosecution of so many citizens, and the law in this case remains a dead letter.

Table 1: Indicators of socio-economic status Russia, Germany, Sweden, Italy, France, Spain and the Netherlands for the first half 2020 of 2020 (EUROSTAT, 2020).

\begin{tabular}{|c|c|c|c|c|c|c|c|}
\hline $\begin{array}{l}\text { Indicators: } \\
\text { Growth(+) } \\
\text { Decline(-) }\end{array}$ & Russia & Germany & Sweden & Italy & France & Spain & $\begin{array}{l}\text { Nether- } \\
\text { lands }\end{array}$ \\
\hline $\begin{array}{c}\text { GDP } \\
\text { dynamics }\end{array}$ & $\begin{array}{c}+0.3 \% \\
\text { (according } \\
\text { to Russtat) } \\
-4.2 \% \\
\text { (according to the } \\
\text { Ministry of } \\
\text { Economic } \\
\text { Development }\end{array}$ & $-2,3 \%$ & $+0,5 \%$ & $-5,3 \%$ & $-5,3 \%$ & $-5,2 \%$ & $-0,4 \%$ \\
\hline 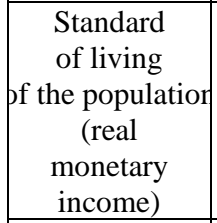 & $\begin{array}{l}-7.7 \\
1 \text { half } \\
2020\end{array}$ & $\begin{array}{l}+2.1 \% \\
\text { I } \\
\text { quarter } \\
\text { of the } \\
2020\end{array}$ & $\begin{array}{c}+0.9 \% \\
\text { I quarter } \\
\text { of the } \\
2020\end{array}$ & $\begin{array}{l}-6.4 \% \\
\text { I quarter } \\
\text { of the } \\
2020\end{array}$ & $\begin{array}{l}+1.3 \% \\
\text { I quarter } \\
\text { of the } \\
2020\end{array}$ & $\begin{array}{c}+0.8 \% \\
\text { I quarter } \\
\text { of the } \\
2020\end{array}$ & - \\
\hline \begin{tabular}{|c|}
$\begin{array}{c}\text { Unemployment } \\
\text { rate }\end{array}$ \\
\end{tabular} & +by 3.7 & $\mathrm{r}+2,4 \%$ & $+0,8 \%$ & $+7,8 \%$ & $+0,8 \%$ & $+1,2 \%$ & $+2,5 \%$ \\
\hline $\begin{array}{l}\text { Mortality } \\
\text { rate }\end{array}$ & $+2,5 \%$ & $+14 \%$ & $+13 \%$ & $+49 \%$ & $+27 \%$ & $+32 \%$ & $+10 \%$ \\
\hline
\end{tabular}

Source: Own study. 
Analysis of indicators of implementation of both models of anti-crisis legal regulation allows us to identify both common features and significant differences. The uniform implementation of prevention programs developed at the international and European levels, in particular by the World Health Organization, has become common.

In addition, the rights and freedoms enshrined in the European Convention of human rights were restricted. However, the scope of these limitations and exclusions varies considerably with respect to the models under consideration. Thus, 10 of the 47 member States of the Council of Europe have officially withdrawn their human rights obligations in connection with the COVID- 19 pandemic (No Torture, 2020).

The differences also consist in the fact that the anti-crisis legal regulation of a restrictive type is "manual" management through numerous by-laws adopted for a time and due to their emergency nature, which contradicted the current legislation both at the Central and regional levels. This type of legal regulation gives extraordinary powers to public authorities. For example, in Spain, Executive power during the pandemic was concentrated in the hands of the President and four Ministers (Royal Decree 463/2020, March, 14). Risk allocation in the market is carried out by government acts retroactively in the interests of weak parties and on the basis of social security.

In Russia information technology mechanisms for total control of the population are being introduced at an accelerated pace, which allow punitive authorities to obtain information not only about the location of citizens, but also about their standard of living and other personal data. In addition, the introduction of a biometric data system is being actively promoted in the context of a worldwide trend that encroaches on privacy and ultimately human freedom.

Analysis of the draft National action plan to normalize business life, restore employment, citizens ' incomes and economic growth in Russia, approved by the RF Government and approved by the President of the Russian Federation, allows us to conclude that the state is building a centralized permitting model of legal regulation that provides for updating mandatory requirements state control (supervision), the implementation of the "regulatory guillotine» mechanism a risk-based approach to the activities of control bodies, introduction of electronic mechanisms for obtaining permits and licenses, development of a notification system for certain types of business activities, simplification of the procedure for withdrawing land plots for state and municipal needs, reduction of the number of sanitary protection zones with special conditions for the use of territory, etc.

The model of soft (creative) legal regulation are based on scientific developments based on the programming method, have a consistent, thoughtful perspective character, are not accompanied by significant restrictions on human rights and generally comply with constitutional requirements. However, in the practical implementation of such a model, is not intended for prohibitions, but for the 
responsibility of disciplined subjects and their self- isolation, and self-restrictions in the full sense of the word can be cited a little. These include Sweden, Germany, the Netherlands, and others.

For example, in Germany, due to the overall negative dynamics of the main economic indicators, results were obtained. It was called the "German miracle". In 84 million people in Germany, 202,735 people were infected, 9092 of them died. Despite the fact that in the country from 1968 was enacted a package of laws on state of emergency, and from 2001 the law on infectious protection of the population, limiting the rights and freedoms prohibitive and quarantine measures was introduced, with the exception of the territory of Bavaria and ensuring pan-European ban on entry into the country.

The key to Germany's success was a systematic anti-crisis approach, including timely and large-scale diagnosis of COVID 19, which, combined with the high level of medical care in the country, financial independence and independence of the German Lands, the presence of clear legal procedures for the introduction of restrictions on human rights and freedoms allowed by law, made it possible to quickly organize treatment of patients. No less important is a high level of discipline, responsibility, and trust in scientists and politicians of German citizens, who voluntarily observe their norms of social distance and other sanitary and epidemiological requirements.

Sweden has also taken the path of recommendatory-permissive, rather than coerciverestrictive measures of legal regulation. Sweden with a population of 10 million. a person has officially recorded 77,377,300 cases of infection and 5,619 deaths from COVID 19, of which about half of the cases occurred in private nursing homes. In neighboring Finland, with a population of 5.5 million people, 7.3 thousand infections and 329 deaths were recorded. In Norway, with 5.4 million people-slightly more than 9 thousand cases of infection and 255deaths, in Denmark with 5.8 million people 13,4 thousand cases of infection and 611deaths.

Thus, in terms of death rates, Sweden has the best indicators compared to Italy, Spain, France and the United Kingdom, but it is six to nine times ahead of Denmark, Norway and Finland, which have used quarantine measures to some extent.

In General, the Swedish system of soft Advisory legal impact is designed for the longterm perspective of maintaining an open society in the state with minimal losses in all areas. Thus, Sweden's GDP fell by only $0.3 \%$ compared with $3.8 \%$ in other EU countries.

\section{Conclusion}

At the end of the research, we will formulate conclusions, which, in our opinion, is important for ensuring a developed (reasonable, peaceful and fair) law, based on the principle of individual freedom and inviolability. In the 21 th century, legal regulation 
cannot be based on compulsory rules but must be based on stable legal believes, secured and protected by legal forms of state power coercion.

The anti -crisis domestic regulation should be carried out only within legal limits, in particular, does not violate the European Convention for the Protection of Human Rights and Fundamental Freedoms and domestic law, without distorting be an objective of the content of the right. At the same time, legal- scientists should reveal the defects of legal formulas of positive law, bringing them to the maximum clarity, certainty and consistency. In particular, the COVID -19 pandemic has shown the need to develop guidelines, recommendations and clear procedures for declaring a state of emergency.

In addition, it is necessary to abandon the mechanistic model of anti-crisis legal regulation and the perception of a space free from legislative regulation as a gap in the law. We consider testing new methods of legal regulation and models of legal thinking to be an indispensable condition for making legally significant decisions that do not lead to failures in legal activities. This is especially important to understand in the digital age, when in addition to the subject - citizen, an active role is played by a creative legal entity - the Creator of new intellectual socially significant products, as well as social connections in virtual information and telecommunications networks.

Analysis of statistical data shows that significant indicators of law enforcement do not improve through the introduction of numerous prohibitions that restrict the freedom of legal communication. On the contrary, total restrictions forced the population to break the legal line, thereby reducing the authority of the law and trust in the legal authorities, creating deformations of legal consciousness, violating the existing legal relations and ties. Thus, by imposing strict restrictions, the state solves immediate problems, but the consequences of these decisions are much more disastrous for society than the actual events that were associated with these restrictions.

Modern anti-crisis legal regulation should be implemented taking into account changes in the regulatory conditions of permitting and Supervisory activities and requires the formation of uniform long-term principles (legality, proportionality, strict justification of the nature of the emergency situation, guarantees against abuse, etc.), the procedure for establishing and internationally evaluating the application of mandatory state requirements. At the same time, the protection of human rights is possible only if the state increases its positive obligations, for example, ensuring guaranteed access of patients to quality medical care and medicines, and taking effective actions to prevent risks to human health and any possible suffering associated with the epidemic.

\section{References:}

Alekseev, N.N. 1919. General doctrine about law: Course of lectures at the Tauride University in 1918/19, Simferopol, 10, 86. 
CoE. 2020a. Council of Europe. Available online:https://rm.coe.int/16809cee30

CoE. 2020b. Council of Europe. Available online: https://rm.coe.int/16809e1d98

CoE. 2020c. Council of Europe. Available online: https://rm.coe.int/16809e0fe5

CoM. 2020. Council of Ministers. Available online:

https://www.esteri.it/mae/resource/doc/2020/03/decreto_del_presidente_del_consiglio dei_ministri_8_marzo_2020_en_rev_1.pdf

DESTAT. 2020. Official German Statistics Data. Available online: https://www.destatis.de/EN/Themes/Labour/Earnings/Real-Earnings-NetEarnings/_node.htm,https://www.insee.fr/en/statistiques/4512017

EUROSTAT. 2020. Data for short-term economic analysis. Available online: https://ec.europa.eu/eurostat/documents/3217494/11098841/KS-BJ-20-007-ENN.pdf/29a047a7-9985-dcdb-c84b-0e3b84f8eddc,

GKS. 2020. Official Rosstat Data. Available online: https://gks.ru/storage/mediabank/hYbb0cRH/oper-06-2020.pdf,

Ilyin, I.A. 1994. General doctrine about law and the state. Collected works, vol. 4, 86-87.

ISTAT. 2020. Official Statistics on the Italian Economy. Available online: https://www.istat.it/it/files//2020/07/MonRep_n5-6_fin.pdf.

Kommersant. 2020. In large cities of the EU, traffic decreased by more than $80 \%$. Available online: https://www.kommersant.ru/doc/4302119

No Torture. 2020. Overview of Restriction of Citizens' Rights in Council of Europe Countries Amid COVID-19 Pandemic. Available online: https://www.pytkam.net/sites/default/files/obzor.pdf. Plan. 2020. Nationwide action plan to normalize business life, restore employment, citizens' incomes and economic growth. Available online: https://e.law.ru/npddoc?npmid=97\&npid=479497\&anchor=tit52\#tit52.

Novgorodtsev P.I. 1909. The modern legal consciousness crisis. Moscow, Kushnerev publ.,13.

Resolution of the constitutional Court of the Russian Federation No. 12-p from 19.04.2016. Collection of legislation of the Russian Federation. 25.04.2016, No. 17, article 2480.

Shatkovskaya, T.V., Epifanova, T.V., Vovchenko, N.G. 2018. The legal regulation mechanism structure transformation in the digital economy. Problems of Economics and Legal Practice, No. 3, 142-146.

Shatkovskaya, T.V., Epifanova, T.V., Vovchenko, N.G., Maslova, I.S. 2020. Goals and Interests in the Law of the Digital Age. Digital Economy: Complexity and Variety vs. Rationality. Springer Nature Switzerland AG, 899-907.

Shatkovskaya, T.V., Solonchenko, A.A., Emirsultanov, Ya.A., Naumenko, Yu.A. 2017. Leading Governments' Legal Initiatives of Innovational Development in the Sphere of Commercialization of Intellectual Products. European Research Studies Journal, Vol. 20, № 3, 98-110.

Sorokin, V.D. 2005. Method of legal regulation: theoretical problems. Selected works, 863864.

TADVISER. 2020. Ministry of Internal Affairs of the Russian Federation. Available online: https://www.tadviser.ru/index.php/Компания:Министерство_внутренних_дел_РФ (МВД)

Touraine, A. 1969. La societe postindustrielle, 53. 